\begin{tabular}{|c|l|}
\hline Title & TDS Measurement of Hydrogen Released from Stainless Steel Oxidized in H2O-Containing A tmospheres \\
\hline Author(s) & Y amauchi, A kira; Y amauchi, Y uji; Hirohata, Y uko; Hino, Tomoaki; Kurokawa, Kazuya \\
\hline Citation & Materials Science Forum, 522(523), 163-170 \\
\hline Issue Date & 2006 \\
\hline Doc URL & http://hdl.handle.net/2115/15824 \\
\hline Rights & the original is available online at www.scientific.net. High-Temperature Oxidation and Corrosion 2005 \\
\hline Type & article (author version) \\
\hline File Information & MSF522-523-163.pdf \\
\hline
\end{tabular}

Instructions for use 


\title{
TDS Measurement of Hydrogen Released from Stainless Steel Oxidized in $\mathrm{H}_{2} \mathrm{O}$-Containing Atmospheres
}

\author{
Akira Yamauchi ${ }^{1, a}$, Yuji Yamauchi ${ }^{2, b}$, Yuko Hirohata ${ }^{2, \mathrm{c}}$, Tomoaki Hino ${ }^{2, \mathrm{~d}}$ and \\ Kazuya Kurokawa, \\ ${ }^{1}$ Center for Advanced Research of Energy Conversion Materials, Hokkaido University, \\ Kita 13 Nishi 8, Kita-ku, Sapporo 060-8628, Japan. \\ ${ }^{2}$ Division of Quantum Science and Engineering, Graduate School of Engineering, \\ Hokkaido University, Kita 13 Nishi 8, Kita-ku, Sapporo 060-8628, Japan. \\ aakira-y@eng.hokudai.ac.jp, byamauchi@qe.eng.hokudai.ac.jp, 'hirohata@qe.eng.hokudai.ac.jp,

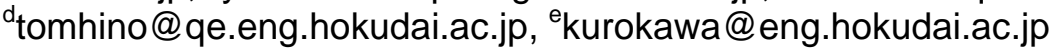

Keywords: oxidation, $\mathrm{H}_{2} \mathrm{O}$ vapor, $\mathrm{Cr}_{2} \mathrm{O}_{3}$ scale, thermal desorption spectroscopy (TDS), hydrogen

\begin{abstract}
Hydrogen dissolved in the $\mathrm{Cr}_{2} \mathrm{O}_{3}$ scale formed on the stainless steel in the $\mathrm{H}_{2} \mathrm{O}$-containing atmospheres is observed by TDS (thermal desorption spectroscopy) measurements. The amount of dissolved hydrogen in the $\mathrm{Cr}_{2} \mathrm{O}_{3}$ scale reaches a maximum about 0.32 mol\% when the $\mathrm{H}_{2} \mathrm{O}$ concentration in the gas reaches 20\%. It was found from GDS (glow discharge spectroscopy) measurements that hydrogen may exist at the oxide scale / substrate interface or in $\mathrm{Cr}_{2} \mathrm{O}_{3}$ scale bounded that interface. However, results from the Vickers hardness and the observation of scale morphology by SEM (scanning electron microscopy), hydrogen dissolved in the $\mathrm{Cr}_{2} \mathrm{O}_{3}$ scale would have little effect on a decrease in the mechanical property of the $\mathrm{Cr}_{2} \mathrm{O}_{3}$ scale. Therefore, hydrogen dissolved in the $\mathrm{Cr}_{2} \mathrm{O}_{3}$ scale may not be main factor of the deterioration of the $\mathrm{Cr}_{2} \mathrm{O}_{3}$ scale.
\end{abstract}

\section{Introduction}

It is well known that an oxide scale $\left(\mathrm{Cr}_{2} \mathrm{O}_{3}\right.$ or $\mathrm{Fe}-\mathrm{Cr}$ spinel oxide) is formed in the initial stage of wet oxidation of $\mathrm{Fe}-\mathrm{Cr}$ alloys and stainless steels. Later, nodule-like oxides are formed locally, and then the alloy shows accelerated oxidation behavior, resulting in a large mass gain [1-5].

Some mechanisms supporting the change from the initially formed $\mathrm{Cr}_{2} \mathrm{O}_{3}$ scale to the nodule-like oxide have been suggested. They can be grouped into two main groups. One group concerns the reaction of a $\mathrm{Cr}_{2} \mathrm{O}_{3}$ scale with $\mathrm{H}_{2} \mathrm{O}(\mathrm{g})$ [6-13]. Asteman et al. [11-12] reported that evaporation of chromia occurred during oxidation of Type $304 \mathrm{~L}$ at $873 \mathrm{~K}$ in humid oxygen. They showed that the evaporation of chromia, probably in the form of $\mathrm{CrO}_{2}(\mathrm{OH})_{2}(\mathrm{~g})$, resulted in the conversion of a Cr-rich oxide scale into a nonprotective iron-rich oxide scale. Moreover, we indicated that the mass loss of $\mathrm{Cr}_{2} \mathrm{O}_{3}$ in $\mathrm{N}_{2}-\mathrm{O}_{2}-\mathrm{H}_{2} \mathrm{O}$ atmospheres was higher than that in $\mathrm{N}_{2}-\mathrm{O}_{2}$ and $\mathrm{N}_{2}-\mathrm{H}_{2} \mathrm{O}$ atmospheres [13].

The other group of possible mechanism relates the degradation of the mechanical property of a $\mathrm{Cr}_{2} \mathrm{O}_{3}$ scale [14-18]. That is, invasion of water vapor into the substrate is caused by deterioration of the mechanical property of the $\mathrm{Cr}_{2} \mathrm{O}_{3}$ scale accompanying the generation of cracks, which is due to dissolution of hydrogen into the $\mathrm{Cr}_{2} \mathrm{O}_{3}$ scale or to an originally brittle property of it. Norby [18] reported that hydrogen or water vapor might affect the oxidation rate and the ability of the scales to deform plastically. He also suggested that possible effect of protons is to enable oxygen to be transported as hydroxide ions. Hultquist et al. [19-21] studied the effect of hydrogen on the growth mechanism of chromia and chromia scale adherence using hydrogen containing chromium. They indicated that the presence of hydrogen leads to accelerate oxidation and poor adherence of the oxide scale.

However, a mechanism that an initially formed $\mathrm{Cr}_{2} \mathrm{O}_{3}$ scale changes into a nodule-like oxide scale is not clear. In a previous paper [13], the reaction of $\mathrm{Cr}_{2} \mathrm{O}_{3}$ scale with $\mathrm{H}_{2} \mathrm{O}$ vapor was investigated. In the 
paper, it was concluded that the evaporation of $\mathrm{Cr}_{2} \mathrm{O}_{3}$ in $\mathrm{N}_{2}-\mathrm{O}_{2}-\mathrm{H}_{2} \mathrm{O}$ atmospheres was a main factor of deterioration of a $\mathrm{Cr}_{2} \mathrm{O}_{3}$ scale. The present paper deals with the examination of the existence of hydrogen in the $\mathrm{Cr}_{2} \mathrm{O}_{3}$ scale formed on Type 430 stainless steel by thermal desorption spectroscopy (TDS). In addition, we discussed change in a mechanical property of $\mathrm{Cr}_{2} \mathrm{O}_{3}$ scales formed in $\mathrm{H}_{2} \mathrm{O}$-containing atmospheres.

\section{Experimental Procedure}

The specimen used in this study was Type 430, and the chemical composition is shown in Table 1. The specimens were cut into $15 \times 5 \times 3\left(10^{-3} \mathrm{~m}\right)$ blocks and then the surfaces were polished up to a micro meter diamond finish. Prior to the oxidation tests, the specimens were ultrasonically cleaned in an ethanol bath. And then the mass and precise size were measured.

Table 1 Chemical composition of Type 430 steel used in the present study [wt\%].

\begin{tabular}{|c|c|c|c|c|c|c|c|c|}
\hline & C & Si & Mn & P & S & Cr & Ni & Fe \\
\hline Type 430 & $\mathbf{0 . 0 6 1}$ & $\mathbf{0 . 4 2}$ & $\mathbf{0 . 4 7}$ & $\mathbf{0 . 0 2 3}$ & $\mathbf{0 . 0 0 1 5}$ & 16.5 & 0.09 & bal. \\
\hline
\end{tabular}

The experimental apparatus used in this study was the same as that used in previous studies [4-5, 13]. Oxidation tests were carried out for up to $21.6 \mathrm{ks}$ at $1173 \mathrm{~K}$ in $\mathrm{N}_{2}-\mathrm{O}_{2},\left(\mathrm{~N}_{2}-\mathrm{O}_{2}\right)-\mathrm{H}_{2} \mathrm{O}$, and $\mathrm{N}_{2}-\mathrm{H}_{2} \mathrm{O}$ atmospheres. $\mathrm{N}_{2}-3 \% \mathrm{O}_{2}$ mixed gas was used as a carrier gas to obtain $\mathrm{N}_{2}-\mathrm{O}_{2}$ and $\left(\mathrm{N}_{2}-\mathrm{O}_{2}\right)-\mathrm{H}_{2} \mathrm{O}$ atmospheres, and $\mathrm{N}_{2}$ gas (purity: $99.999 \%$ ) was used as a carrier gas to obtain $\mathrm{N}_{2}-\mathrm{H}_{2} \mathrm{O}$ atmospheres. The water vapor concentrations in the carrier gases were 6.9, 12.2, 19.7, and 45.4 vol. \%. Carrier gases with these $\mathrm{H}_{2} \mathrm{O}$ concentrations were obtained by bubbling the $\mathrm{N}_{2}-\mathrm{O}_{2}$ mixed gas or the $\mathrm{N}_{2}$ gas through distilled water maintained at $313,323,333$, and $353 \mathrm{~K}$. The flow rate was $3.3 \times 10^{-6} \mathrm{~m}^{3} \mathrm{~s}^{-1}$ at room temperature. For the oxidation test, the specimen was quickly inserted into the hot zone of a reaction tube (internal diameter: $2.5 \times 10^{-2} \mathrm{~m}$ ) in an electric furnace maintained at a desired temperature and atmosphere. The specimen was heated and then quickly removed from the hot zone and cooled in air.

After the oxidation tests, the specimen was moved to the TDS apparatus [22-23] for measurement of the trapped amount of hydrogen. Typical pressure before the TDS measurement was about $1 \times 10^{-7}$ $\mathrm{Pa}$. In the TDS measurements, the specimen was located on a heater made by tantalum. The specimen was linearly heated from RT to $1023 \mathrm{~K}$ in $1500 \mathrm{~s}$ and kept at $1023 \mathrm{~K}$ for $300 \mathrm{~s}$. The heating rate was $0.5 \mathrm{Ks}^{-1}$. During the heating, the amount of desorbed hydrogen was measured by a quadrupole mass spectrometer (QMS). In this study, the method that uses the value of $S \times K$, where $S$ represents the pumping speed for hydrogen and $K$ reciprocal of sensitivity of QMS for hydrogen, is required to calibrate gas sensitivity [24]. The equation for calibration of gas sensitivity is written as follows.

$\mathrm{S} \times \mathrm{K}\left[\mathrm{mol} \mathrm{A} \mathrm{s}^{-1}\right]=\mathrm{q}\left[\mathrm{mol} \mathrm{s}^{-1}\right] / \mathrm{i}[\mathrm{A}]$

Where $q$ represents desorption rate and $i$ intensity of QMS signal. The value of $\mathrm{S} \times \mathrm{K}$ for hydrogen was $4.7 \mathrm{~mol} \mathrm{~A}^{-1} \mathrm{~s}^{-1}$, which was estimated by using a hydrogen standard leak. In this experiment using TDS, this value was used for calibration of gas sensitivity. Desorption rate of hydrogen is given by the following equation.

Desorption rate $\left[\mathrm{m}^{-2} \mathrm{~s}^{-1}\right]=\left(\mathrm{M}-\mathrm{M}_{0}\right)[\mathrm{A}] \times(\mathrm{S} \cdot \mathrm{K})\left[\mathrm{mol} \mathrm{A} \mathrm{s}^{-1}\right] \times \mathrm{N}_{\mathrm{A}}\left[\mathrm{mol}^{-1}\right] / \mathrm{A}\left[\mathrm{m}^{2}\right]$

Where $\mathrm{M}$ represents the signal intensity of desorption hydrogen from specimen and chamber, $\mathrm{M}_{0}$ the 
signal intensity of desorption hydrogen from chamber, $\mathrm{N}_{\mathrm{A}}$ Avogadro's number, and A surface area of specimen.

Vickers microhardness of oxide scale was measured by Micro Hardness Tester using HMV-1T instrument (Shimadzu Co., Japan). Surface morphology of oxide scale was observed by SEM using JSM-T20 instrument (JEOL, Japan). Further, depth profiling analyses of the oxide scale were carried out by glow discharge spectroscopy (GDS) using Jobin-Yvon 5000RF instrument (Horiba Ltd., Japan).

\section{Results and Discussion}

The desorption behavior of hydrogen from specimen. Figure 1 indicates typical hydrogen desorption spectra in the specimens oxidized in various conditions. QMS signal intensity of hydrogen from the specimen oxidized for $21.6 \mathrm{ks}$ in $\mathrm{N}_{2}-3 \% \mathrm{O}_{2}$ as a function of time is shown in Fig. 1(a). In this figure it can be seen that the QMS signal intensity of hydrogen from specimen is identical with that from chamber. It is obvious that desorption hydrogen from specimen oxidized in the $\mathrm{N}_{2}-\mathrm{O}_{2}$ atmosphere without $\mathrm{H}_{2} \mathrm{O}$ vapor is negligible. The desorption rate of hydrogen from the specimens oxidized for $21.6 \mathrm{ks}$ in $\mathrm{N}_{2}-2.4 \% \mathrm{O}_{2}-19.7 \% \mathrm{H}_{2} \mathrm{O}$ and $\mathrm{N}_{2}-19.7 \% \mathrm{H}_{2} \mathrm{O}$ as a function of time are shown in Fig. 1(b) and (c). It can be noted from these figures that specimens oxidized in $\mathrm{H}_{2} \mathrm{O}$-containing atmospheres emit hydrogen clearly in contrast to the specimen oxidized without $\mathrm{H}_{2} \mathrm{O}$ vapor. The desorption rates of hydrogen increase with increasing heating time, and the curves reach to the peak at a certain temperature and fall rapidly after that. The peaks of the desorption rate of hydrogen shift to high temperature side with increasing oxidation time.
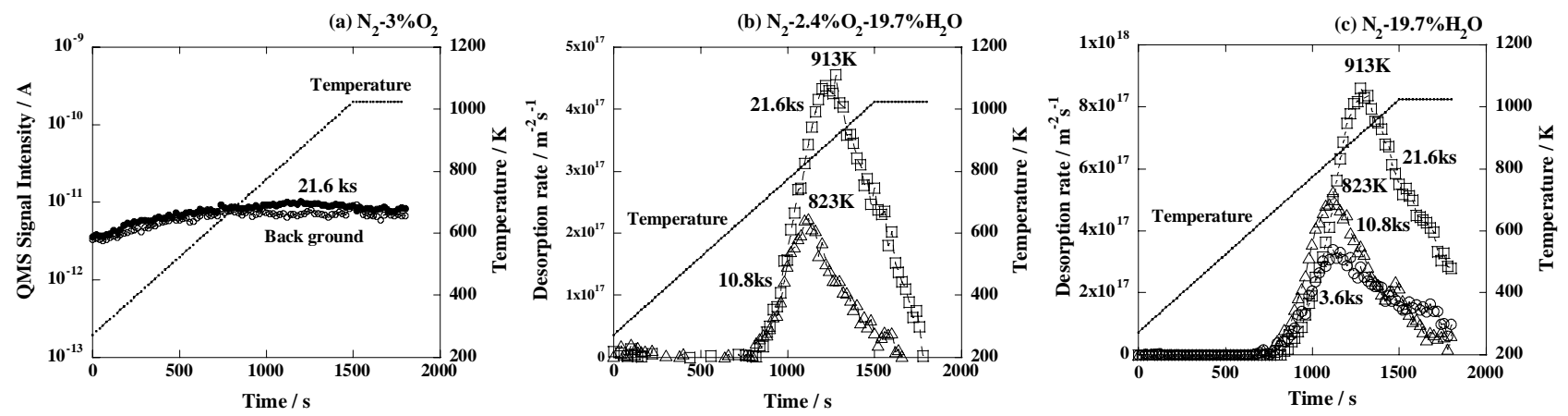

Fig. 1 QMS signal intensity and thermal desorption spectra of Type 430 oxidized for various times at $1173 \mathrm{~K}$ in $\mathrm{N}_{2}-3 \% \mathrm{O}_{2}(\mathrm{a}), \mathrm{N}_{2}-2.4 \% \mathrm{O}_{2}-19.7 \% \mathrm{H}_{2} \mathrm{O}\left(\right.$ b) , and $\mathrm{N}_{2}-19.7 \% \mathrm{H}_{2} \mathrm{O}(\mathrm{c})$ atmospheres.

The dependence of $\mathrm{H}_{2} \mathrm{O}$ vapor concentration in atmosphere on the behavior of hydrogen release was examined. Figure 2 represents the desorption rate of hydrogen from the specimens oxidized for $21.6 \mathrm{ks}$ in various $\mathrm{H}_{2} \mathrm{O}$ vapor concentration atmospheres as a function of time. The desorption rate of hydrogen reaches the maximum point around 800 - $900 \mathrm{~K}$ and increases with increasing $\mathrm{H}_{2} \mathrm{O}$ concentration. Further, the peaks of the desorption rate of hydrogen tend to move high temperature side with increasing $\mathrm{H}_{2} \mathrm{O}$ concentration. It is unclear in this experiment which part of specimen such as scale or alloy substrate emits hydrogen. In order to determine the part emitted hydrogen, the specimens treated in following conditions were measured by TDS.

Sample1: as-received Type 430.

Sample2: Type 430 oxidized for $21.6 \mathrm{ks}$ at $1173 \mathrm{~K}$ in $\mathrm{N}_{2}-2.4 \% \mathrm{O}_{2}-19.7 \% \mathrm{H}_{2} \mathrm{O}$ atmosphere. 


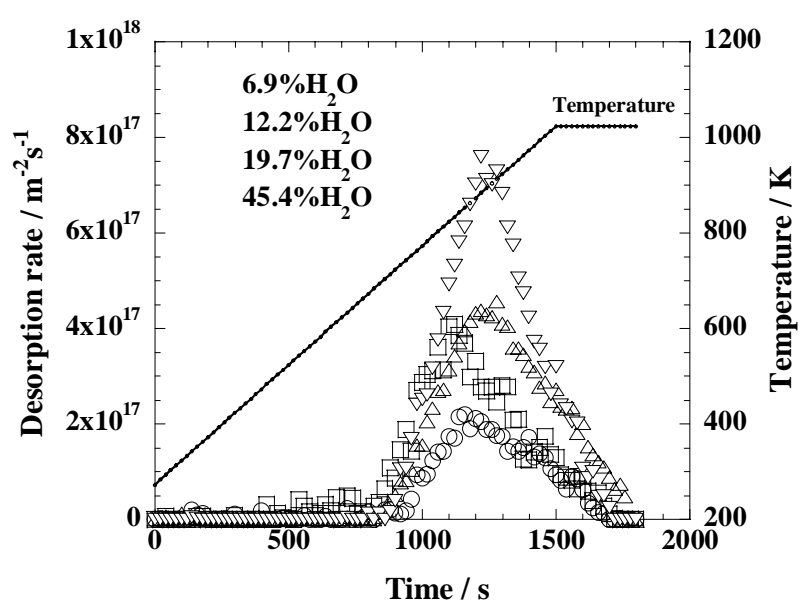

Fig. 2 Thermal desorption spectra of Type 430 oxidized for $21.6 \mathrm{ks}$ at $1173 \mathrm{~K}$ in $\left(\mathrm{N}_{2}-3 \% \mathrm{O}_{2}\right) \quad-\mathrm{X} \% \mathrm{H}_{2} \mathrm{O} \quad(\mathrm{X}=6.9, \quad 12.2$, 19.7, 45.4) atmospheres.

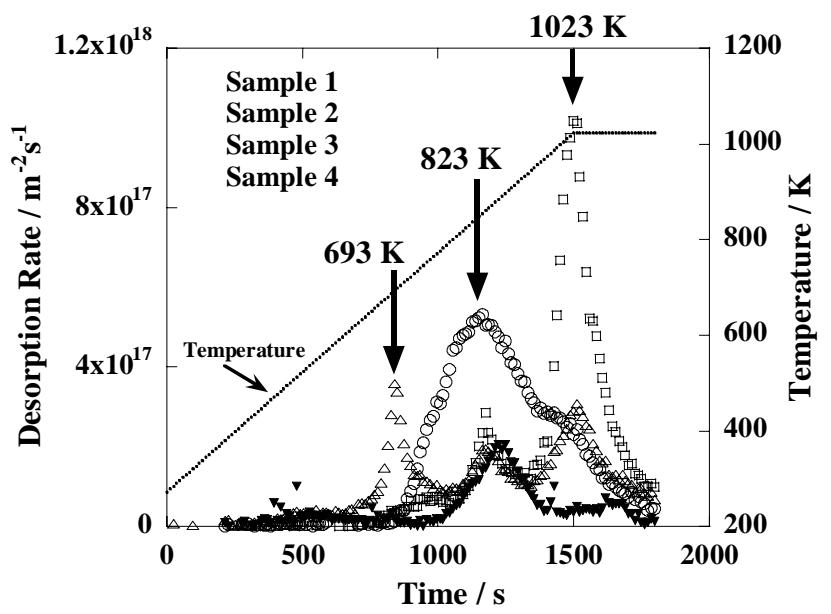

Fig. 3 Thermal desorption spectra of Type 430 that produced on various conditions.

Sample3: Type 430 substrate removed oxide scales after TDS measurement of sample 2

Sample4: Type 430 substrate removed oxide scales after oxidation for $21.6 \mathrm{ks}$ at $1173 \mathrm{~K}$ in $\mathrm{N}_{2}$ $-2.4 \% \mathrm{O}_{2}-19.7 \% \mathrm{H}_{2} \mathrm{O}$

The results of TDS measurements about the above specimens are shown in Fig. 3. Peaks of the hydrogen desorption rate can be classified into three main groups. Evolution curves of samples 3 and 4, which were removed oxide scales, have maxima at 693 and $1023 \mathrm{~K}$, respectively. Those spectra are derived from the Type 430 substrate. On the other hand, the peak at $823 \mathrm{~K}$ is obtained by all specimens (Sample 1 to 4). The spectra of Sample 1, 3 and 4 are almost the same, but that of Sample 2 shows a strong peak as compared with those (Sample 1, 3 and 4). It is therefore speculated that hydrogen liberated at $823 \mathrm{~K}$ is mainly derived from the oxide scale formed on the specimen in the $\mathrm{N}_{2}-\mathrm{O}_{2}-\mathrm{H}_{2} \mathrm{O}$ atmosphere. The difference in area of the spectrum at $823 \mathrm{~K}$ between sample 2 and other samples without oxide scale is thought to come from the oxide scale.

In addition, the mol amount of hydrogen per surface area was calculated by integration of the hydrogen desorption rate measured by TDS, and the mol amount of $\mathrm{Cr}_{2} \mathrm{O}_{3}$ formed on the surface of Type 430 by using the mass gain of Type 430 oxidized in $\mathrm{H}_{2} \mathrm{O}$-containing atmosphere. In this case, it is assumed that Type 430 forms only the $\mathrm{Cr}_{2} \mathrm{O}_{3}$ scale and all hydrogen emitted by heating dissolves into the $\mathrm{Cr}_{2} \mathrm{O}_{3}$ scale. Fig. 4 indicates the relationship between the concentration of $\mathrm{H}_{2} \mathrm{O}$ vapor in oxidized atmospheres and mol\% of hydrogen dissolved in $\mathrm{Cr}_{2} \mathrm{O}_{3}$ scale on the basis of above calculations. The dissolved hydrogen amount increases with $\mathrm{H}_{2} \mathrm{O}$ concentration in oxidized atmosphere, and there is almost no dependence of that on $\mathrm{H}_{2} \mathrm{O}$ concentration that is $20 \%$ or more. It is estimated that the dissolved hydrogen amount in $\mathrm{Cr}_{2} \mathrm{O}_{3}$ scales formed in $\mathrm{N}_{2}-\mathrm{O}_{2}-\mathrm{H}_{2} \mathrm{O}$ atmospheres that has $20 \% \mathrm{H}_{2} \mathrm{O}$ concentration or more is about $0.32 \mathrm{~mol} \%$.

The distribution of hydrogen in oxide scale. Although it is found from TDS measurements that hydrogen dissolves into $\mathrm{Cr}_{2} \mathrm{O}_{3}$ scales formed in $\mathrm{H}_{2} \mathrm{O}$-containing atmospheres, it is not clear how hydrogen is distributed in the $\mathrm{Cr}_{2} \mathrm{O}_{3}$ scale. Thus, in order to clarify the distribution of hydrogen in a $\mathrm{Cr}_{2} \mathrm{O}_{3}$ scale, GDS measurements were done.

Fig. 5 shows GDS depth profiles of Type 430 oxidized for $21.6 \mathrm{ks}$ at $1173 \mathrm{~K}$ in $\mathrm{N}_{2}-3 \% \mathrm{O}_{2}$ (a), $\mathrm{N}_{2}-2.4 \% \mathrm{O}_{2}-19.7 \% \mathrm{H}_{2} \mathrm{O}$ (b) and $\mathrm{N}_{2}-19.7 \% \mathrm{H}_{2} \mathrm{O}$ (c) atmospheres. In Fig. 5 (a), GDS analysis indicates small amount of hydrogen at the gas/oxide interface and no amount of hydrogen in the oxide scale, 


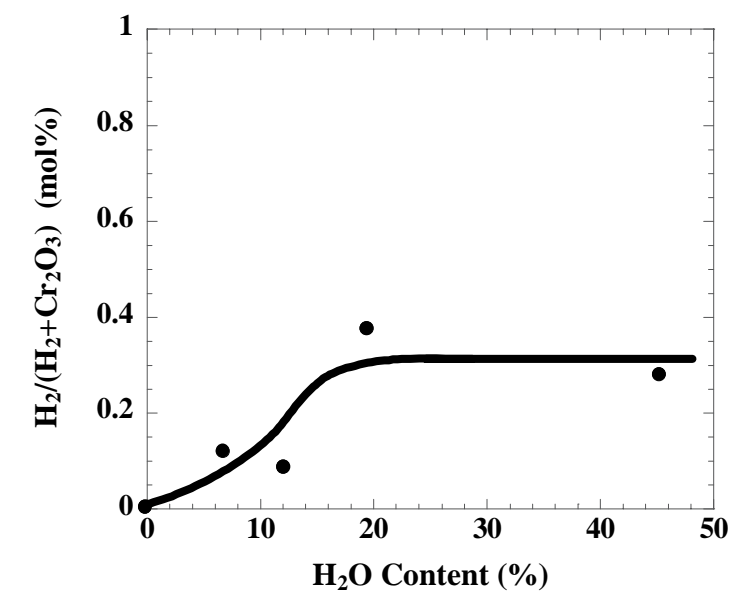

Fig. $4 \mathrm{H}_{2} \mathrm{O}$ content dependence of hydrogen dissolution in Type 430 oxidized for $21.6 \mathrm{ks}$ at 1173 $\mathrm{K}$ in $\left(\mathrm{N}_{2}-3 \% \mathrm{O}_{2}\right)-\mathrm{X} \% \mathrm{H}_{2} \mathrm{O}(\mathrm{X}=6.9,19.7,45.4)$ atmospheres.

oxide/substrate interface and stainless steel substrate. The existence of hydrogen at the gas/oxide interface is caused by water adsorbed on the surface of the specimen because the amount of oxygen increases simultaneously on the surface of the specimen. On the other hands, in Fig. 5 (b) and (c), furthermore the measurable amount of hydrogen at the oxide/substrate interface is detected. Although the state of hydrogen in the specimen is not clear, this result suggests that hydrogen exists at the oxide scale/substrate interface or in $\mathrm{Cr}_{2} \mathrm{O}_{3}$ scale part adjacent to the interface.
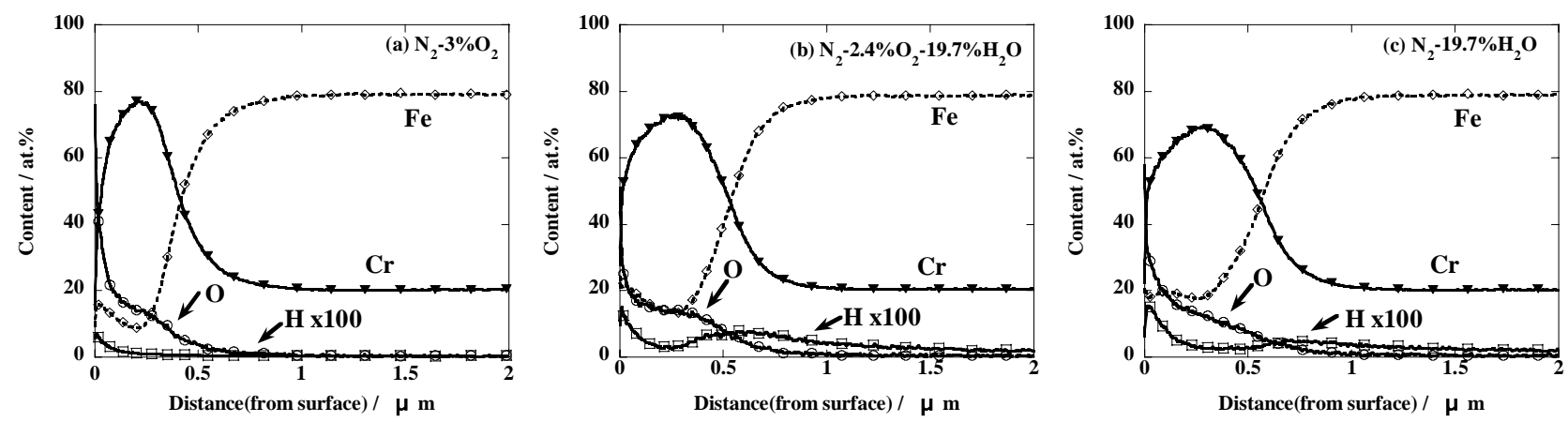

Fig. 5 GDS profile of Type 430 oxidized for $21.6 \mathrm{ks}$ at $1173 \mathrm{~K}$ in $\mathrm{N}_{2}-3 \% \mathrm{O}_{2}$ (a), $\mathrm{N}_{2}-2.4 \% \mathrm{O}_{2}-19.7 \% \mathrm{H}_{2} \mathrm{O}(\mathrm{b})$, and $\mathrm{N}_{2}-19.7 \% \mathrm{H}_{2} \mathrm{O}(\mathrm{c})$ atmospheres.

Vickers hardness measurement of scale and observation of scale morphology. These results of our experiment definitely show that hydrogen exists in the $\mathrm{Cr}_{2} \mathrm{O}_{3}$ scale formed in $\mathrm{H}_{2} \mathrm{O}$-containing atmospheres. However, it is not clear whether dissolved hydrogen affects the ability of plastic deformation of the oxide scale and causes the brittle fracture of oxide scale. Thus, we considered the brittleness of oxide scale formed in $\mathrm{H}_{2} \mathrm{O}$-containing atmospheres. The scale morphology of Type 430, which was oxidized for $21.6 \mathrm{ks}$ in various atmospheres, after Vickers hardness measurement by loading 0.05 and $2 \mathrm{~kg}$ is shown in Fig. 6. In the condition of loading $0.05 \mathrm{~kg}$ (Fig. 6 (a) and (b)), the hollow in the specimen oxidized in the $\mathrm{N}_{2}-2.4 \% \mathrm{O}_{2}-19.7 \% \mathrm{H}_{2} \mathrm{O}$ atmosphere (Fig. 6 (a)) is clearly observed, but the hollow in the specimen oxidized in the $\mathrm{N}_{2}-3 \% \mathrm{O}_{2}$ atmosphere (Fig. 6 (b)) is 
obscurely observed. It is speculated that the oxide scale formed in $\mathrm{N}_{2}-3 \% \mathrm{O}_{2}$ is harder than that formed in $\mathrm{N}_{2}-2.4 \% \mathrm{O}_{2}-19.7 \% \mathrm{H}_{2} \mathrm{O}$. In the condition of loading $0.1 \mathrm{~kg}$, the value of $\mathrm{Hv}$ in $\mathrm{N}_{2}-3 \% \mathrm{O}_{2}$ is about 340 and that in $\mathrm{N}_{2}-2.4 \% \mathrm{O}_{2}-19.7 \% \mathrm{H}_{2} \mathrm{O}$ about 240 . The value of $\mathrm{Hv}$ in $\mathrm{N}_{2}-19.7 \% \mathrm{H}_{2} \mathrm{O}$ is about equal to that in $\mathrm{N}_{2}-2.4 \% \mathrm{O}_{2}-19.7 \% \mathrm{H}_{2} \mathrm{O}$. Therefore, the Vickers hardness in $\mathrm{H}_{2} \mathrm{O}$-containing atmospheres decreases in comparison with that in dry atmosphere irrespective of the existence of oxygen. Furthermore, the appearance of the scale fracture by loading $2 \mathrm{~kg}$ (Fig. 6 (c) and (d)) was observed. In Fig. 6(d) (the specimen oxidized in $\mathrm{N}_{2}-3 \% \mathrm{O}_{2}$ ), it is observed that the cracks occur around the hollow and oxide scale peels away partially. On the other hand, in Fig. 6(c) (the specimen oxidized in $\mathrm{N}_{2}-2.4 \% \mathrm{O}_{2}-19.7 \% \mathrm{H}_{2} \mathrm{O}$ ), the occurrence of cracks and the exfoliation of oxide scale is not observed. These results suggest that the $\mathrm{Cr}_{2} \mathrm{O}_{3}$ scales formed in $\mathrm{H}_{2} \mathrm{O}$-containing atmospheres improve the brittlement in comparison to that formed in $\mathrm{N}_{2}-3 \% \mathrm{O}_{2}$.

Based on the above results, it may not be adequate that hydrogen dissolved into a $\mathrm{Cr}_{2} \mathrm{O}_{3}$ scale results in degradation of the mechanical properties of the $\mathrm{Cr}_{2} \mathrm{O}_{3}$ scale. Therefore, it can be speculated that deterioration of a $\mathrm{Cr}_{2} \mathrm{O}_{3}$ scale is mainly due to a reaction of $\mathrm{Cr}_{2} \mathrm{O}_{3}$ with $\mathrm{H}_{2} \mathrm{O}$ vapor. In fact, as shown in Fig. 7, SEM observation demonstrated that oxide grains comprising the oxide scale formed in $\mathrm{N}_{2}-2.4 \% \mathrm{O}_{2}-19.7 \% \mathrm{H}_{2} \mathrm{O}$ seem to be isolated. In other words, the oxide scale seems to be appreciably rough in comparison with that formed in $\mathrm{N}_{2}-\mathrm{O}_{2}$. For above results, it seems reasonable to suppose that the hardness of scales formed in $\mathrm{H}_{2} \mathrm{O}$-containing atmospheres decreases apparently, that is to say, brittlement of a $\mathrm{Cr}_{2} \mathrm{O}_{3}$ scale is apparently improved. This results from volatile species by reaction of
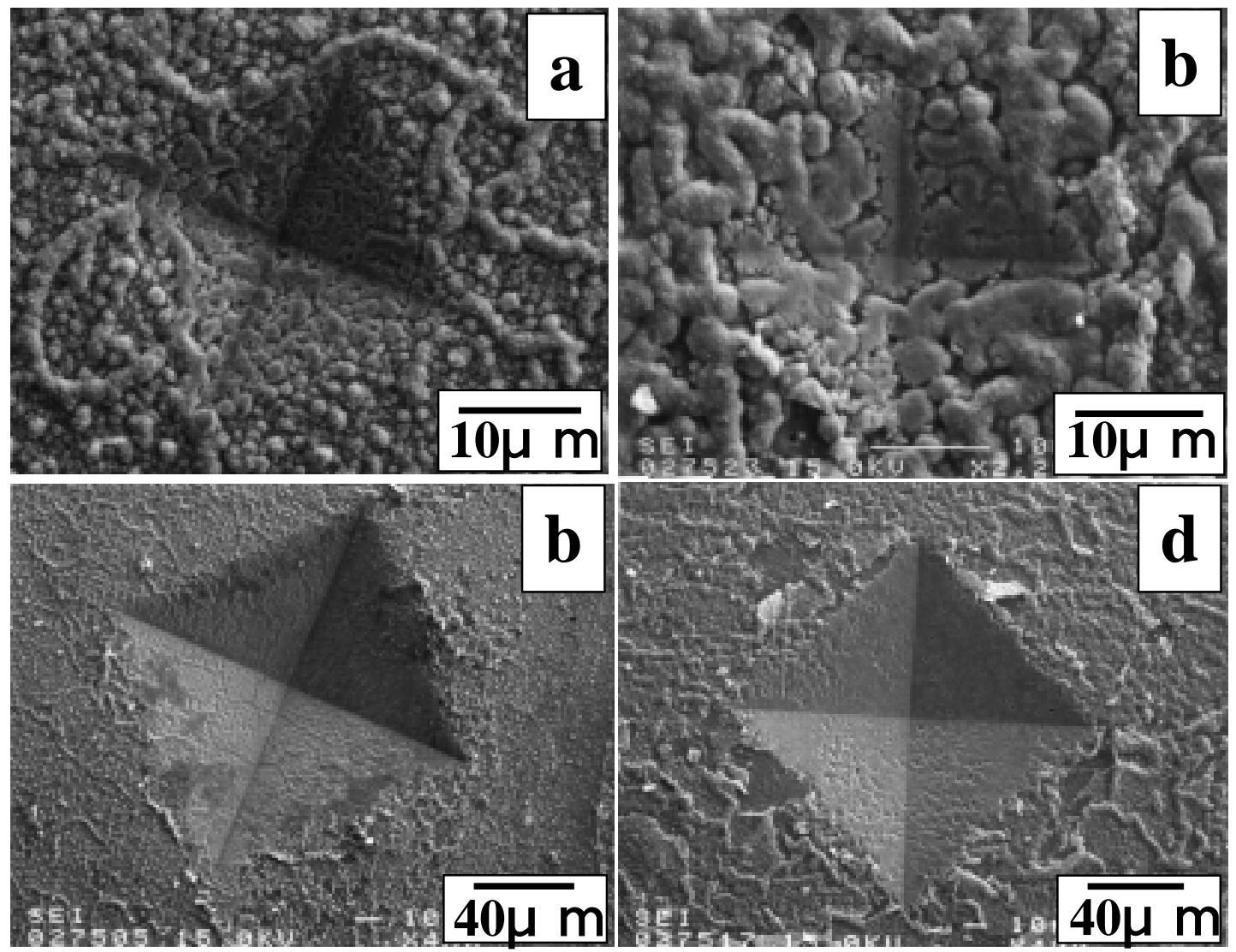

Fig. 6 SEM images showing chromia surface with hollow by Vickers hardness formed on Type 430 oxidized for $21.6 \mathrm{ks}$ at $1173 \mathrm{~K}$ in $\mathrm{N}_{2}-2.4 \% \mathrm{O}_{2}-19.7 \% \mathrm{H}_{2} \mathrm{O}$ ((a) and (c)) and $\mathrm{N}_{2}-3 \% \mathrm{O}_{2}((\mathrm{~b})$ and (d)) atmospheres. (a) and (b) is in the condition of loading 0.05 $\mathrm{kg}$, (c) and (d) is in that of loading $2 \mathrm{~kg}$. 

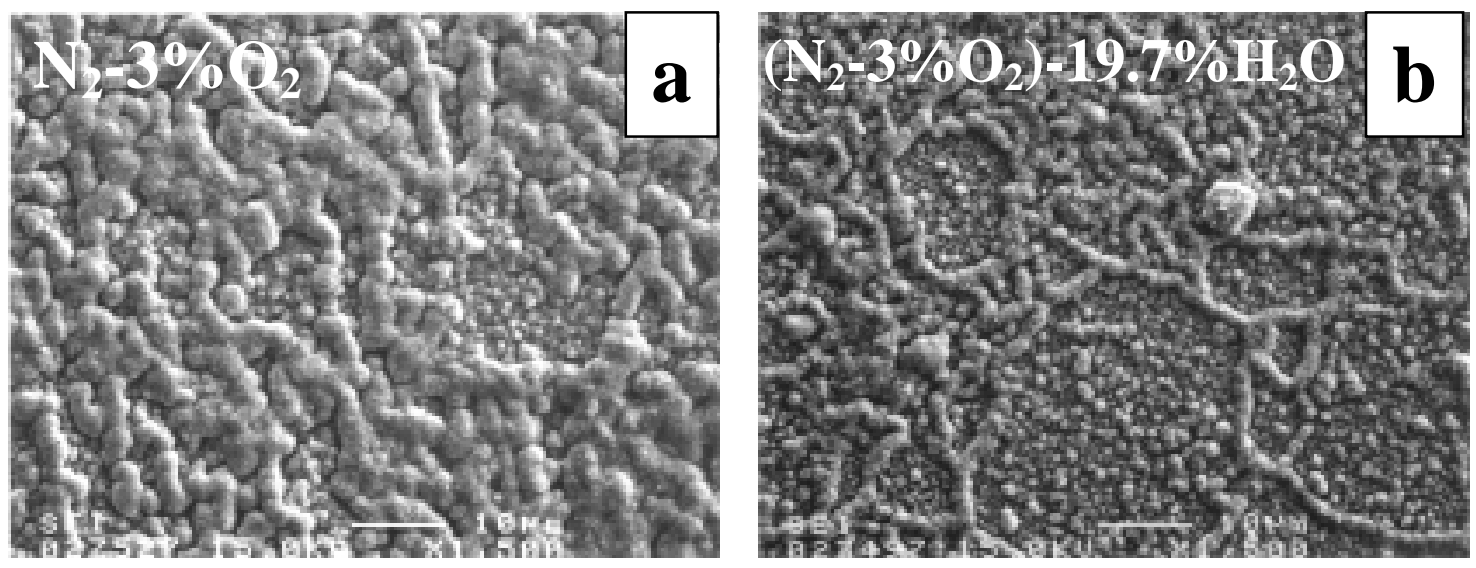

Fig.7 SEM images showing chromia surface formed on Type 430 oxidized for $21.6 \mathrm{ks}$ at $1173 \mathrm{~K}$ in $\mathrm{N}_{2}-3 \% \mathrm{O}_{2}$ and $\mathrm{N}_{2}-2.4 \% \mathrm{O}_{2}-19.7 \% \mathrm{H}_{2} \mathrm{O}$ atmospheres.

$\mathrm{Cr}_{2} \mathrm{O}_{3}$ with $\mathrm{H}_{2} \mathrm{O}$ and oxygen [13].

Based on the above discussion, it could not say that the dissolved hydrogen in $\mathrm{Cr}_{2} \mathrm{O}_{3}$ scale degrades the mechanical property of a $\mathrm{Cr}_{2} \mathrm{O}_{3}$ scale. It can be supposed that brittlement of $\mathrm{Cr}_{2} \mathrm{O}_{3}$ scales formed in $\mathrm{H}_{2} \mathrm{O}$-containing atmospheres are apparently improved in comparison with that in dry atmosphere.

\section{Conclusions}

The measurement of hydrogen amount in the specimen and the analysis of hydrogen distribution in $\mathrm{Cr}_{2} \mathrm{O}_{3}$ scale were carried out by TDS and GDS. Furthermore, the influence of hydrogen on the brittlement of $\mathrm{Cr}_{2} \mathrm{O}_{3}$ scale was examined. The following conclusions were obtained:

1. It can be noted that hydrogen dissolves in the $\mathrm{Cr}_{2} \mathrm{O}_{3}$ scale formed in $\mathrm{H}_{2} \mathrm{O}$-containing atmosphere. The amount of dissolved hydrogen in the $\mathrm{Cr}_{2} \mathrm{O}_{3}$ scale reaches a maximum (about $0.32 \mathrm{~mol} \%$ ) when the $\mathrm{H}_{2} \mathrm{O}$ concentration in the gas reaches $20 \%$.

2. It is found from the TDS measurement and the GDS analysis that hydrogen exist, especially near the oxide scale/substrate interface.

3. Since the $\mathrm{Cr}_{2} \mathrm{O}_{3}$ scales formed in $\mathrm{H}_{2} \mathrm{O}$-containing atmospheres have porous structure, the hardness and the brittlement of that decreases apparently in comparison with those formed in dry atmospheres.

4. The dissolved hydrogen doesn't affect the deterioration of $\mathrm{Cr}_{2} \mathrm{O}_{3}$ scale.

\section{Acknowledgements}

The authors would like to thank Mr. A. Hirano and Ms. H. Kawano of Horiba Ltd., Tokyo, Japan for GDS measurements.

\section{References}

[1] C. T. Fujii and R. A. Meussner, J. Electrochem. Soc. Vol. 111 (1964), p. 1215

[2] A. Rahmel and J. Tobolski, Corros. Sci. Vol. 5 (1965), p. 333

[3] K. Kusabiraki, T. Sugihara, and T. Ooka, Tetsu-to-Hagane Vol. 77 (1991), p 123 
[4] A. Yamauchi, K. Kurokawa, H. Takahashi, and Y. Takada: J. Japan Inst. Metals Vol. 64 (2000), p. 359

[5] A. Yamauchi, K. Kurokawa, H. Takahashi, and Y. Takada: Materials at High Temperatures Vol. 18 (2001), p. 111

[6] C. S. Tedmond Jr.: J. Electrochem. Soc. Vol. 113 (1966), p. 766

[7] H. C. Graham and H. H. Davis: J. Amer. Ceram. Soc. Vol. 54 (1971), p. 89

[8] C. A. Stearns, F. J. Kohl, and G. C. Fryburg: J. Electrochem. Soc. Vol. 121 (1974), p. 945

[9] Y-W Kim, and G. R. Belton: Met. Trans. Vol. 5 (1974), p. 1811

[10] B. B. Ebbinghaus: Combust. Flame Vol. 93 (1993), p. 119

[11] H. Asteman, J. -E. Svensson, L. -G. Johansson, and M. Norell: Oxid. Met. Vol. 52 (1999), p. 95

[12] H. Asteman, J. -E. Svensson, M. Norell, and L. -G. Johansson: Oxid. Met. Vol. 54 (2000), p. 11

[13] A. Yamauchi, K. Kurokawa, and H. Takahashi: Oxid. Met. Vol. 59 (2003), p. 517

[14] I. Kvernes, M. Oliveira, and P. Kofstad: Corros. Sci. Vol. 17 (1977), p. 237

[15] P. Kofstad: Oxid. Met. Vol. 24 (1985), p. 265

[16] P. Kofstad: High-Temperature Corrosion, (Elsevier Applied Science, London 1988).

[17] S. Jianian, Z. Longjiang and L. Tiefan: Oxid. Met. Vol. 48 (1997), p. 347

[18] T. Norby: J. Phys. IV Vol.3 (1993), p. 99

[19] G. Hultquist, B. Tveten, and E. Hornlund: Oxid. Met. Vol. 54 (2000), p. 1

[20] B. Tveten, G. Hultquist, and T. Norby: Oxid. Met. Vol. 52 (1999), p. 221

[21] B. Tveten, G. Hultquist, and D. Wallinder: Oxid. Met. Vol. 55 (2001), p. 279

[22] H. Yanagihara, I. Fujita, T. Hino and T. Yamashina: J. Nucl. Mater. Vol. 220-222 (1995), p. 856

[23] H. Yanagihara, Y. Yamauchi, T. Hino, Y. Hirohata, and T. Yamashina: J. Nucl. Mater. Vol. 241-243 (1997), p. 1098

[24] Y. Aihara: Master Eng. Thesis, Hokkaido University, 1996. 